\title{
EMPLEO DOMÉSTICO EN NAVARRA. REFLEXIONES EN TORNO A LA PERCEPCIÓN DE MUJERES SUDAMERICANAS INMIGRADAS, SOBRE SU EXPERIENCIA EN EL ÁMBITO DEL CUIDADO
}

\author{
Domestic work in Navarra \\ Reflections on the perception of South American immigrant women \\ according to their experience in care area
}

Hernán Riquelme Brevis *

\begin{abstract}
RESUMEN
El presente trabajo se configura desde la contingencia de la migración latinoamericana que experimentó España en la última década (2001-2011). Se enfatizará en la comunidad de Navarra, ciudad de Pamplona. Para efectos prácticos se analiza un estudio de caso que tiene como muestra a mujeres sudamericanas inmigradas que se dedican al trabajo doméstico. Se identificaron los elementos claves, que permitieron el anclaje teórico-conceptual, para explorar en los procesos del cuidado social. Como consecuencia de lo mencionado, se ofrecen ejes reflexivos que permiten ahondar en algunas de las motivaciones y sensaciones que produjeron el enrolamiento de las mujeres en el trabajo doméstico, atendiendo a las definiciones sociológicas que articulan el discurso-praxis de la población migrante.
\end{abstract}

Palabras clave: Migración, opresión de género, cuidado social, precarización laboral.

\footnotetext{
*Universidad Autónoma de Chile. Temuco, Chile. Correo electrónico: h.riquelmebrevis@gmail.com Artículo recibido el 13 de enero de 2013. Aceptado el 25 de agosto de 2013.
} 


\begin{abstract}
This paper is presented on the contingency of Latin American migration lived in Spain between (2001-2011). The community of Navarra, Pamplona will be emphasized. For practical purposes, a case study that works with a sample of South American immigrant women whose job is domestic work is analyzed. Key elements were identified and allowed the theoretical-conceptual basis to explore social care processes. As a result of what is mentioned above, thoughtful focal points that allow deeper considerations into some of the motivations and feelings that produced the enrollment of women in domestic work are provided based on sociological definitions that connect the praxis-discourse of migrant population.
\end{abstract}

Keywords: Migration, oppression gender, social care, precarious work.

\title{
INTRODUCCIÓN
}

El fenómeno social de la inmigración ${ }^{1}$ ha de ser analizado desde las complejidades que presenta el proceso para un sujeto que se abre a nuevas realidades tanto en términos culturales, como económicos. Para ello, resulta fundamental la utilización de una perspectiva integradora que dé cuenta de la experiencia subjetiva de las informadoras, ello con la finalidad de ahondar en el aspecto epistemológico del cuidado-trabajo doméstico. Cabe señalar que en España "El crecimiento de la población de más de 65 ańos, pasó de 3,3 millones de personas en 1970 a más de 6,6 millones en el año 2000 (el 16,6\% de la población)” (San José, 2011: 27), lo cual produce un segundo impacto asociado al "aumento del número de personas en situación de dependencia por razones de enfermedad, discapacidad o limitación por los cambios producidos en las tasas de supervivencia a enfermedades crónicas, alteraciones congénitas y accidentes laborales y de tráfico"(Op. cit., 28).

A este segundo factor se suma la condicionante del cambio en el modelo tradicional de familia, en el cual durante la última década se han incorporado tres millones de mujeres al mercado del trabajo, fenómeno que "hace imprescindible una revisión del sistema tradicional de atención basado en el cuidado de la familia por las mujeres" (Op. cit.). Si a los tres elementos mencionados se ańade la variable del cuidado como eje transversal el escenario se complejiza, puesto que existe un amplio sector de mujeres inmigradas encargadas del cuidado.

${ }^{1}$ La Organización de las Naciones Unidas estima que para el año 2008 un total de 200 millones de personas vivían en un país diferente al suyo, las mujeres representan casi la mitad de los migrantes. 
En el presente trabajo se pretende analizar la percepción de las mujeres inmigradas sudamericanas que trabajan en hogares navarros². Se tomará como eje analítico la relación que existe entre el trabajo doméstico y la construcción social del cuidado. El aporte académico surge desde la exploración en el discurso elaborado por las mujeres trabajadoras, el cual proporciona conocimientos para posteriores comentarios que se detallarán en las páginas venideras.

\section{CONSIDERACIONES TEÓRICAS}

Desde el corpus teórico, y considerando la crítica feminista hacia la corriente económica desarrollada principalmente desde la década de los 70's, se tendrá presente la temática del cuidado, velando por revalorizar el concepto he intentado soslayar su feminización.

Remitiéndonos a Mandel (1979), para comenzar a describir los elementos teóricos constitutivos de manera genérica, cabe señalar que "El estado burgués se distingue, sin embargo, de todos los estados que le han precedido, por un aspecto [...] la separación entre esfera privada y esfera social (la cual) es llevada al extremo por la generalización, característica exclusiva de este modo de producción de la producción mercantil, es decir, de la competencia de todos contra todos" (173). En la sociedad capitalista, al existir una forma particular de división entre esfera privada y esfera social, se origina una polarización del concepto de familia vinculado al tránsito histórico producido desde el feudalismo al capitalismo, lo cual abre un espacio que se relaciona estrechamente con una tipología de trabajo doméstico que se abstrae de la esfera social.

El proceso social y particular, según Artous (1982) se compone de "elementos aislados de la producción social [...] organizándose en un lugar geográficamente distinto de la producción social" (18). Prácticas referidas a la relación cultural servil mujer-hombre desde el trabajo doméstico, proceso que relega a la mujer al aspecto privado y que permite pesquisar algunos indicios de opresión por periodos (desde la constante) mediante la posición de las mujeres en la historia de la sociedad.

En relación a la variable género y su campo de operaciones, destaca la definición que apunta a una polifuncionalidad operativa de la relación género-

\footnotetext{
2 No se explicitará analíticamente el marco normativo, el cual provee otro tipo de análisis asociado al aspecto políticogubernamental. Se sugiere para este tipo de análisis revisar a Fagundes, Denise. "Trabajar de interna: o trabalho doméstico das imigrantes latinoamericanas e os paradoxos da regularização da imigração na Espanha de Zapatero", Fazendo Gênero 8 - Corpo, Violência e Poder, 2008. También se sugiere consultar el Real Decreto 1620/2011 (España).
} 
clase, en la que "de la misma manera que un lenguaje especifico en cuanto al género influye en cómo se piensan o dicen las cosas, las formas narrativas arquetípicas de Occidente que dan por sentada la presencia de un protagonista masculino influyen en la forma en que arman cuentos acerca de las mujeres" (Conway, 2000: 24).

Conway, al sostener que la cuestión de género se refleja en forma de frontera mutable, permite desarrollar un análisis en perspectiva del lenguaje y como éste se funda en la creación de realidades, proceso que facilita la comprensión de la construcción social de la masculinidad y de la feminidad.

Desde la noción de familia ${ }^{3}$ se presenta la forma conceptual anclada en la tradición clásica de la sociología que la distingue como base fundamental de la sociedad, lo cual no implica necesariamente la separación de ésta de los componentes estructurales de la sociedad. Más aún, desde lo que se comprende mediante la traslación a nuevas conceptualizaciones a partir de la transformación política de la sociedad. En relación a ello sostiene Elizabeth Jelin (2010: 25):

"La diversidad de formas de familia está ligada a transformaciones sociales, económicas y culturales. Esto es así porque la familia no puede ser vista como una institución aislada sino como parte de un entramado de instituciones y prácticas sociales, donde el Estado y la legislación, las creencias y prácticas religiosas, los comportamientos económicos y otras formaciones sociales actúan simultáneamente para configurarla”.

La relación casa-trabajo se puede considerar como esencial para dar cuenta de la analogía conceptual mujer-trabajo, dado que existe una naturalización de las condiciones sociales que mantienen a la mujer en distintos niveles de producción. Por consiguiente, se puede sostener que "La mujer es la principal responsable de las tareas reproductivas, tareas que pueden ser diferenciadas en tres niveles: en primer lugar, las mujeres tienen a su cargo la reproducción biológica, que en el plano familiar significa gestar y tener hijos y en el social se refiere a los aspectos sociodemográficos de la fecundidad" “(Jelin, 2000: 46), proceso que se sostiene en la reproducción biológica (desde el cuerpo de la mujer). Segundo, "se ocupan de la organización y gran parte de las tareas de la reproducción cotidiana, o sea de las tareas domésticas que permiten el mantenimiento y la subsistencia de los miembros de su familia" (Op. cit.), proceso de trabajo doméstico (desde el cuidado). Tercero, "desempeñan un papel fundamental en la reproducción social [...] especialmente en el cuidado y la socialización temprana de los niños y niñas,

3 Como parte de un proceso de construcción social.

${ }^{4}$ Idea de la labor doméstica inspirada en Larguía y Dumoulin (1976). 
transmitiendo normas y patrones de conducta aceptados y esperados. Sin embargo, esto no es todo, porque las mujeres también desarrollan, en forma creciente, tareas productivas en el mercado de trabajo, y siempre han participado en las actividades productivas de los emprendimientos familiares" (Op. cit.).

La reproducción humana, en términos sociales y biológicos, corresponde al proceso que se experimenta desde lo que aparecería como un triple proceso. Este último, el proceso de reproducción de fuerza de trabajo diario (desde el trabajo doméstico), permite un previo acercamiento a la noción del trabajo ligado al mercado en contraposición al hogar. Al existir la división casa (privado)/ trabajo (público-social), se avanza en la consideración social de la reproducción biológica y el trabajo doméstico como factores directos de la creación de la figura "ama de casa”, lo cual insta a mantener un estado de alerta ante la visión que considera las prácticas del cuidado como algo naturalizado en la mujer. Sujeto a lo anterior se encuentra la conformación del Poder ${ }^{5}$, el cual se vislumbra como un entramado político, y que se desenvuelve desde/hacia las relaciones sociales. En las actividades ligadas al cuidado el poder resuena como una acción que predomina, principalmente por la relación patrón/trabajadora (desde el enfoque del cuidado en el trabajo doméstico). Por lo cual, "A escala societal el poder es un espacio y una malla de relaciones sociales de explotación/dominación/conflicto articuladas, básicamente, en función y en torno de la disputa por el control de los siguientes ámbitos [...] (3) el sexo, sus productos y la reproducción de la especie; [...] (5) la autoridad y sus instrumentos, de coerción en particular" (Quijano, 2000: 28).

El análisis de Quijano, en relación a los campos de acción del poder, contribuye en la direccionalidad que mantiene desde el quehacer social. Los puntos 3 y 5 son fundamentales en la compresión actitudinal que conlleva a situaciones de explotación de clase y opresión de género, principalmente debido a (punto 3) la visión que tienen los empleadores sobre las mujeres inmigradas, quienes al encontrarse socialmente sin redes de apoyo son objeto de factible abordaje desde la oferta laboral desregulada, la cual es utilizada como "enganche" para desatar prácticas asociadas al abuso en términos laborales (salarios bajos, violencia psicológica, violencia físico-sexual, y sobrecarga laboral).

El poder, desde la figura masculina y empleadora recae en el sometimiento hacia la figura femenina encargada de organizar el cuidado doméstico, relación

\footnotetext{
${ }_{5}^{5}$ El poder, como praxis grandilocuente, debe presentarse en la estructuración conceptual dado que se ciñe directamente con el aspecto laboral (poder de uno sobre otro), para ello puede complementarse la conceptualización con el aporte del filósofo Adolfo Sánchez Vásquez. Disponible en: <http://www.mxfractal.org/BU2Sanchez.htm>.
} 
jerárquica que constrińe a la segunda. Respecto al punto 5 la autoridad, interpretada por el empleador masculino y/o su pareja (jefes de hogar) mediante el instrumento de coerción, representado en la oportunidad laboral brindada a una sudamericana en el mayor de los casos sin papeles en regla y sin mayores redes sociales de apoyo, supone un doble compromiso. El primero, de carácter simbólico, que se asociaría a la oportunidad de tener trabajo en un contexto adverso, y que a su vez reflejaría una cuota simbólica adicional: la fidelidad hacia el patrón(a). El segundo, de carácter material, ligado al salario y la cobertura de las necesidades de subsistencia básicas (alojamiento, comida, etc.) en caso de tener acceso a ellas. Por otra parte, el término de "cuidados" se presenta en la conformación que implica el circuito de tareas y disposiciones asociadas al bienestar humano para enfrentar la vida, se aborda desde lo físico y lo afectivo, evidenciando experiencias personales al momento de socializar el término.

Para acotar el concepto (puesto que involucra dimensiones muy extensas) se opta por tener presente la visión que lo asocia al cuidado directo ${ }^{7}$ de las personas desde lo higiénico-afectivo hacia la tercera edad, como también lo indirecto que supone la responsabilidad hacia los cuidados coyunturales, plasmando así "una frontera para los cuidados no tan cercana como para involucrar solo el cuido directo de personas, ni tan amplia que incluya toda actividad que repercuta y busque el bienestar de las personas" (Carcedo, 2011: 20).

\section{ASPECTOS METODOLÓGICOS}

\subsection{El discurso de las mujeres inmigradas}

La raíz metodológica se cińe, desde la práctica cualitativa, a entrevistas ${ }^{8}$ semi-estructuradas realizadas a mujeres sudamericanas que ejercen el trabajo doméstico en la ciudad de Pamplona y sus alrededores. Para sistematizar la información obtenida se hará hincapié en tres ejes problemáticos: opresión de

\footnotetext{
${ }^{6}$ Para profundizar en las instituciones (Estado, familia, mercado, otros sectores) que ofertan y encargan labores asociadas al cuidado, el Diamante del Cuidado entregaría solidas concepciones al respecto, matizando la carga, de una u otra manera, dependiendo de las particularidades del tipo de sociedad en cuestión.

${ }^{7}$ El cuidado afectivo, es de carácter simbólico pero no por eso menos importante, puesto que se evidencia en los comentarios de las trabajadoras una necesidad principalmente económica hacia la ocupación.

${ }^{8}$ Las entrevistas se sostuvieron con mujeres sudamericanas con un rango etario de 20-30, en la ciudad de Pamplona durante el año 2011 (desde el espacio entregado por los estudios de posgrado cursado en la Universidad Pública de Navarra). Mediante la muestra por conveniencia, se entrevistaron a mujeres sudamericanas que trabajaban en la Comunidad Foral de Navarra, el contacto se estableció en la ciudad de Pamplona. Para tener una visión complementaria se recomienda consultar Vilches, Carlos. "La acogida a la población inmigrada que reside en Navarra". Taller de Sociología s. I, Pamplona-Iruña, 2007.
} 
género, trabajo precario, y marco legal. Ejes que afloran desde el énfasis discursivo que desarrollaron las entrevistadas.

Las experiencias de las mujeres sudamericanas se tornan de vital importancia para dar cuenta de las problemáticas experimentadas por ellas en el desarrollo previo y posterior al enrolamiento laboral doméstico, lo cual permite un escenario que denota las particularidades y generalidades de sus modos de percibir su participación y la de sus empleadores, como también de la nueva sociedad de acogida. Cabe señalar que "El servicio doméstico ocupa a 750.000 personas en España, de las cuales el $95 \%$ son mujeres y el 60\% personas inmigrantes” (San José, 2011: 168).

Para evidenciar y organizar los ejes que claves que se obtuvieron de la sistematización de la información se exhibirán fragmentos claves que permiten un posterior enlace con la matriz conceptual.

\subsection{El Carácter de clase y el marco legal}

Las mujeres inmigradas conciben el proceso de movilidad geográfica y social a partir de una experiencia vital que, de una u otra forma, impactará en la "nueva vida". Es necesario señalar que existe un porcentaje no menor ${ }^{9}$ de mujeres inmigrantes que poseen estudios superiores finalizados o la secundaria finalizada, lo cual las posicionaría como pertenecientes a la clase media en su país de origen, proceso que se revierte al momento de enfrentarse con el país de acogida, cambiando su estatus social debido a la coyuntura del proceso migratorio, que en términos laborales se sustenta en la precarización ${ }^{10}$.

"Muchas venimos de familias medias sabes, la cosa se complica con los papeles, con la tramitación y eso... una vienen con la ilusión de mejorar la vida... la familia... darles un mejor pasar. Pero cuesta tanto conseguir los trámites, hacer los papeles y nada cambia sin eso"(E: 1).

"No se dan cuenta que la gran mayoría de las que estamos aqui tienen profesión, yo soy peruana y hay muchos peruanos aqui que son profesores, son doctores, tengo mi prima que es

\footnotetext{
${ }_{9}$ Con el grupo de mujeres que se estableció contacto el año 2011, el 70\% tenía estudios superiores.

${ }_{10}$ Para tener una lectura paralela Razavi, Shara. "La economía política y social del cuidado en un contexto en desarrollo. Problemas conceptuales, preguntas de investigación y opciones de políticas". Programa Género y desarrollo № 3. Instituto de investigación de Naciones Unidas para el Desarrollo Social, 2007. Se discute con dos grandes antecedentes 1) Mujeres en Desarrollo y 2) Discusión sobre el trabajo doméstico, se considera necesario rescatar de la crítica la visión sobre la subvaloración del concepto de cuidado. Para los objetivos del presente artículo el aporte de la autora reside en la necesidad de entregar poder a las proveedoras del cuidado, como también la "forma en que la sociedad aborda los problemas relativos al cuidado tiene importantes consecuencias para la igualdad de género, ya sea que se aumenten las capacidades y opciones de las mujeres y hombres, o se perpetúe el confinamiento de las mujeres a las funciones tradicionales relacionadas con la feminidad y la maternidad" (Razavi, 2007: 7. Consultado en Binstock, 2009: 42).
} 
enfermera, mi padre está en construcción y es policía. La gente española tiene una idea que somos analfabetos y es por eso que se quieren aprovechar" (E: 5).

La forma de regular el proceso por parte de las instituciones públicas amparadas en el Estado se asocia a la posesión de los permisos legales (visados), lo cual genera un quiebre de expectativas entre las inmigradas que repercute en su moral y en las formas de vivenciar su nueva vida, sometiéndose al nuevo marco legal, aspecto que genera una desprotección ante el marco normativo, aumentando su situación de vulnerabilidad.

El cuidado, a través del trabajo doméstico, se puede percibir en un primer momento como una herramienta que permite generar altos ingresos económicos ${ }^{11}$, es en este instante de "ilusión” donde surge la suposición de ver en el cuidado una labor mediante la construcción socio-histórica de la feminidad.

El "ganarse la vida" a través del oficio de trabajadora doméstica surge como una actitud asumida conscientemente, y no ha de ser azaroso que la relación cultural existente entre países con altos índices de inequidad de género ${ }^{12}$ y el constructo de la jerarquización de género, haga surgir en las mujeres sudamericanas inmigradas la posibilidad de ver en el cuidado una herramienta de trabajo real, resultando casi espontánea la relación desde un nuevo escenario geográfico con las ganancias obtenidas en el ejercicio del cuidado ${ }^{13}$.

\subsection{Del trabajo precario a la explotación, la jornada interminable}

El gobierno del hogar se transformó en servicio privado; la mujer se convirtió en la criada principal, sin tomar ya parte en la producción social (Engels, 2008: 26). En las siguientes citas se condensa la matriz conceptual del enfoque cuidadoprecarización laboral. Se expresa de manera considerable la visión subjetiva de las mujeres y el enfoque material de las construcciones sociales sobre el mercado laboral y las incidencias de éste en la ocupación precaria de las inmigradas.

"No puedo dejar el trabajo de ahora... vamos, ique cuesta encontrar! Que si [...] a mi me pagan 400 euros en una casa, ella sabe que es poco, y asi me he movido para conseguirme

\footnotetext{
${ }_{11}$ Una acción que permitiría cierto grado de mejor calidad de vida para la familia de la trabajadora que se encuentra en su país de origen dado (entre otras variables) el valor de la moneda euro.

${ }_{12}$ Para profundizar en datos que puedan abrir la lectura en clave de participación socioeconómica femenina en Latinoamérica ver Lamelas, Nélida y Aguayo, Eva. "Desigualdad de género en Latinoamérica desde la perspectiva de los indicadores de desarrollo humano", Revista Galega de Economía, 19 (2): 1-15, 2010. Como también Martínez, Juliana y Voorend, Koen. “Sistemas de patriarcado y regímenes de bienestar en América Latina. ¿Una cosa lleva a la otra?” (Documento de Trabajo). Fundación Carolina, N³7, 2009.

13 El trabajo doméstico, asimilado culturalmente en su país de origen, se vuelve la principal fuente de trabajo.
} 
otras casas... es una vaina... El otro día le dije a la señora que me subiera el sueldo y se puso complicada. No me paga bien por todo lo que le cuido su casa" (E: 2).

"Uno sabe que hay muchas que quieren trabajar como uno y cobrarán menos que uno, hay mucha gente pidiendo menos euros por trabajar en lo mismo. Cogen a los que menos cobren, ellos felices con ahorrarse unos euros... y ahi queda una... esperando poder trabajar. Hay una chica colombiana, amiga mía, que cobra por día [...] trabaja en muchas casas para hacerse el sueldo" (E: 1).

La identificación por parte de las inmigradas sobre el flujo migratorio como un indicador determinante de una mayor demanda de trabajo sobre el mercado doméstico, y el desamparo social que vivencian, al no encontrarse en situación regular, supone un doble proceso de precarización.

El primero, asociado a lo que Mandel (1979) sostiene en relación al capitalismo y el modo de producción mercantil ("todos contra todos"), en el cual la cuestión laboral se somete a un proceso de desregularización debido, de cierta forma, a que los Estados (de origen y receptor ${ }^{14}$ ) se abstraen de la problemática, $y$ deja en situación de desamparo al grupo de inmigrantes en situación irregular, lo cual las obliga a buscar posibilidades mediante el trabajo informal o negro, ello conlleva a enfrentarse al empleador sin ningún tipo de defensa desde el marco legal.

El segundo proceso, asociado al salario (desde la mantención durante el trabajo y la sobrevivencia ${ }^{15}$ ) como medio mercantil, que a su vez, comercializa la existencia de las trabajadoras domésticas, sustentándose en una explotación laboral que no está regulada debido al carácter de informalidad.

\subsection{La opresión de género, inmigración y violencia}

No estamos acostumbrados a asociar el patriarcado con la fuerza. Su sistema socializador es tan perfecto, la aceptación general de sus valores tan firme y su historia en la sociedad humana tan larga y universal, que apenas necesita el

\footnotetext{
${ }^{14}$ Se considera que los Estados de origen de las mujeres sudamericanas, de algún modo, obligan a estas a migrar en busca de mejores oportunidades laborales, lo cual debiese abrir la autocrítica debido a que no son suficientemente capaces de beneficiar equilibradamente a su población mediante políticas públicas, generando una masa de sujetos que venden su fuerza de trabajo en países desarrollados. (factores como inequidad y la pobreza en Sudamérica se tornan agravantes), más allá de la discusión de la libertad individual, es una constante histórica la inmigración latinoamericana y africana hacia los países europeos y Estados Unidos, inmigración que persigue un "mejor vivir". Si bien los Estados de Bolivia, Ecuador, Perú y Colombia presentan una política proteccionista hacia la migración, sigue existiendo escasa interlocución entre la población emigrada y los Estados de origen. Ver discusión en Araujo, Lorena y Eguiguren, María Mercedes. "La gestión de la migración en los países andinos: entre la securitización y los vínculos diaspóricos" (Dossier central). Quito: FLACSO sede Ecuador. Programa de Sociología, Sistema de Información sobre Migraciones Andinas, (no.3, abril 2009): 2-10.

15 Revisar en Marx, Karl. Manuscritos Económicos y Filosóficos (Primer manuscrito). Barcelona: Editorial Altaya, 1997.
} 
respaldo de la violencia (Millet, 1969: 13). La situación de opresión que viven las mujeres inmigradas que se vinculan a la labor doméstica se enlaza estrechamente con la Reproducción social y la Autoridad e instrumentos de coerción, de los cuales se desprende la opresión de género para desatar vejámenes directos ${ }^{16}$.

Las mujeres inmigradas padecen tanto de su condición irregular, como de su construcción social de mujer, al someterse a un sistema de precarización desde el trabajo en la esfera privada. La vulnerabilidad afecta, desde una perspectiva psicosocial, su integridad como sujeto y ello se sustenta, en parte no menor, mediante la Autoridad (desde el poder) por parte del patrón, quien violenta tanto económicamente, como físicamente a las trabajadoras.

"Estaba trabajando en Ermitagaña, en una casa hermosa... el tío, al principio se mostraba respetuoso, con el tiempo cuando su señora se iba a trabajar se puso a proponer cosas "que si follamos y te pago más" me decía, yo no sabia qué hacer, me dejo helada [...] lo evitaba... y no podia dejar el trabajo porque sin trabajo no como... creen que porque somos extranjeras estamos dispuestas a todo" (E: 3).

"Mientras buscaba trabajo me presentaron a un hombre, mis amigas de Caritas ${ }^{17}[\ldots]$ y resultó ser todo un depravado, en la entrevista me dijo que con mi cuerpo podia ganar muchos más bailándole que trabajando en su casa, y le dije que no y me fui [... a a una le da rabia, porque quieren tener sexo, y yo simplemente quiero trabajar, los españoles abusan, huelen nuestra necesidad y se aprovechan de eso. Yo soy honrada, trabajadora y educada" (E: 5).

La doble condición explotación-opresión, sustentada en la posición histórica y social de la mujer, se ve trasladada a la sociedad moderna. La doble condición refleja la relación de reproducción social/privada de la sociedad de clases que afecta a la clase subalterna de manera directa, a lo cual se añade la cuestión de género vivenciada por las mujeres inmigradas, en donde el carácter violento de la relación demanda laboral de fuerza femenina/oferta laboral masculinizada, deja fisuras al momento de percibir la organización social del cuidado como un acto que en este escenario está ligado a la visión imperante de carácter machista y opresiva. Postura masculinizante que enfoca de manera alienante la inclusión de la oferta sexual dentro de las actividades que realizan las trabajadoras del cuidado doméstico.

La violencia explícita requiere un análisis particular desde el cuidado, el ámbito privado y la escasa visibilidad que entrega el espacio (el hogar) para la ${ }_{16}$ Para profundizar en el concepto de violencia hacia las mujeres ver Maqueira, Virginia y Sánchez, Cristina (Comps.), Violencia y sociedad patriarcal. Madrid: Editorial Pablo Iglesias, 1990.

${ }_{17}$ Organización de carácter religioso que, entre otras funciones, colabora con la población migrante. 
socialización de las problemáticas que afectan a un sector no menor de las mujeres inmigradas precarizadas. Ello puede asociarse a la indefensión laboral que les aqueja, encontrándose fragmentadas organizativamente como trabajadoras.

\section{REFLEXIONES FINALES}

El fenómeno social de la inmigración ${ }^{18}$, el envejecimiento producido en la sociedad española, la exigua regulación/fiscalización laboral hacia las trabajadoras domésticas y las precarias condiciones laborales, como algunas de las tantas variables en cuestión, obliga a prestar atención al ámbito del cuidado desde el rol que cumple en la conformación productiva de la sociedad, lo cual involucra la contratación de personal (ya sea de forma legal o en negro) y las condiciones a las cuales se somete la trabajadora al momento de ejercer la actividad.

Las mujeres inmigradas se encargan de la labor del cuidado de forma más activa que las autóctonas, aspecto que está supeditado a la remuneración que supone esta actividad para ellas, como también la significancia peyorativa que involucra la actividad desde las autóctonas. Las trabajadoras (en su mayoría) depositan una cantidad (remesa) de su sueldo a su familia de origen en Sudamérica, y no perciben el trabajo doméstico como algo permanente, más bien lo realizan como una labor temporal.

Cabe señalar que la precarización que vivencian las trabajadoras domésticas se visualiza a partir de dos grandes focos. El primero (nivel macro), desde la figura del Estado de origen ${ }^{19}$, el cual al no prestar atención de forma directa al fenómeno de la migración, es responsable indirecto de la precarización de sus ciudadanos inmigrados, quienes no se benefician en su país de origen por la existencia de un desarrollo sustentable (mediante políticas públicas) que se traduzca en mejorías de la calidad de vida, proceso que obliga ${ }^{20}$ a estas mujeres a emigrar (de forma irregular y con la condicionante de la precarización), dejando a sus familias atrás

\footnotetext{
${ }_{18}$ En el nuevo escenario (2013) de crisis social y económica que azota con mayor profundidad a Europa y principalmente a algunos países del sur (Grecia, Italia, España, Portugal, Chipre, entre otros), resulta necesario preguntarse si es que la población inmigrada sigue manteniendo la hegemonía del trabajo doméstico, y de ser así que porcentaje de la población autóctona se ha insertado en esta labor. Ello con la finalidad de ver las fluctuaciones que ha experimentado la relación migración-trabajo doméstico.

19 No debe ser azaroso que los casos consultados involucren en esta actividad a mujeres que en su mayoría proceden de: Perú Colombia, Ecuador, Bolivia y Paraguay. Si bien no es temática abordada en el presente trabajo, el considerar las características culturales y económicas que atraviesan estos países resultaría sugerente para un acercamiento particular de la construcción social de masculinidad y feminidad.

${ }^{20} \mathrm{Si}$ bien se puede contrastar este comentario con la "libertad de elección", no se polemizará con esta percepción ya que en el presente trabajo la "libertad" se condiciona a normas y acciones dentro de un marco social hegemónico prestablecido, que moldea las posibilidades de deliberación individual.
} 
para rebuscárselas mediante el trabajo doméstico. También el Estado receptor ${ }^{21}$, que al no fiscalizar el trabajo en negro justifica el proceso, igualmente de forma implícita.

El segundo, desde la familia que acoge al inmigrante (nivel micro) para ejercer labores, aunque no se puede generalizar, la constante demuestra que existe un trato basado en la opresión y explotación hacia las trabajadoras, lo cual se traduce en bajos salarios o no pago de salarios, abuso físico y psicológico, no regularización de documentos, etcétera.

El cuidado, al relacionarse en el presente trabajo como una labor desarrollada en el ámbito privado, desde una relación jerárquica patrón-trabajadora y de acciones enmarcadas en el contexto de asistencia física y de aseo hacia la familia contratante, no puede abstraerse de las condicionantes materiales que involucran esta actividad. El ser mujer, sudamericana, en situación irregular, sin grandes redes sociales de apoyo y con la carga psicosocial de haber dejado (en la mayoría de los casos) a una familia en su lugar de origen, las obliga a vender su fuerza de trabajo para lograr la subsistencia individual y la de sus pares, en varias ocasiones en un contexto carente de los imaginarios sociales que supone un trabajo al tenor de una sociedad desarrollada.

Si bien existe una amplia discusión en torno al origen y causas del patriarcado y/o sistema de estratificación sexual, la generación de la división de géneros ha logrado permear todos los aspectos de la vida social. Es así como surge, de algún modo, la figura de la mujer de clase subalterna, encargada de las labores del cuidado familiar en un contexto de desarrollo económico y social ejemplificador (Europa) como muestra de un trabajo que supone un enorme esfuerzo para la producción social en todas las áreas.

El cuidado es una actividad cotidiana, de inmensa utilidad para colaborar en la mantención del equilibrio, tanto social como biológico, de los sujetos que conforman la sociedad. Sin sujetos que se especializaran mediante labores asociadas al cuidado, se presentaría un escenario adverso en términos de salubridad, reproducción biológica y producción social, económica y cultural. Urge visibilizar la problemática y asumir responsabilidades, generando mecanismos políticos (y si es que ya existen reforzar su visibilidad) que velen por mejorar las condiciones laborales de las trabajadoras domésticas.

${ }^{21}$ No se trata de generar una cacería de inmigrantes en situación ilegal o irregular, más bien de fiscalizar las políticas sociales de recepción y políticas (públicas) de cooperación hacia los inmigrantes. 
Finalmente, es necesario señalar que el cuidado como actividad transversal e inherente de la sociedad, no podrá ser valorado como tal tanto en cuanto no se inste a posicionar la actividad más allá (pero teniéndolo presente) de la importancia de género, clase, o nacionalidad, es decir, apuntar a visualizar el cuidado como una actividad que pueda comprenderse y desarrollarse por todos y todas, valorizando la experiencia que aporta desde lo afectivo y material.

\section{REFERENCIAS}

Artous, Antoine. Los orígenes de la opresión de la mujer. Barcelona: Fontamara, 1983.

Binstock, Georgina y Cerruti, Marcela. Familias latinoamericanas en transformación: desafios y demandas para la acción pública. Santiago de Chile: Publicación de las Naciones Unidas, 2009.

Carcedo, Ana; Chaves, María José y Lexartza, Larraitz. Cadenas globales de cuidados: El papel de las migrantes nicaragüenses en la provisión de cuidados en Costa Rica. Santo Domingo: ONU Mujeres, 2011.

Conway, Jill. El género. La construcción cultural de la diferencia sexual. México D. F.: Programa Universidad Estudios de Género, 2000.

Engels, Federic. El origen de la familia, la propiedad privada y el estado. Madrid: Alianza Editorial, 2008.

Esquivel, Valeria; Faur, Eleonor y Jelin, Elizabeth. Las lógicas del cuidado infantil. Entre las familias, el estado y el mercado. Buenos Aires: Instituto de Desarrollo Económico y Social, 2012.

Jelin, Elizabeth. Pan y afectos. La transformación de las familias. Colección popular. Buenos Aires: Fondo de Cultura Económica, 2010.

Mandel, Ernest. El capitalismo tardio. México D. F.: Era, 1979.

Millet, Kate. Política sexual. Madrid: Cátedra, 1969. 
Pérez, Amaia y López, Silva. "Desigualdades a flor de piel: cadenas globales de cuidado. Concreciones en el empleo del hogar y políticas públicas”. Madrid: ONU Mujeres, 2011.

Quijano, Aníbal. "Colonialidad del poder y clasificación social”, Journal of World System Research 4/2, (2000): 342-386.

Razavi, Shahra. "La economía política y social del cuidado en un contexto en desarrollo. Problemas conceptuales, preguntas de investigación y opciones de políticas”. Programa Género y desarrollo No 3. Instituto de investigación de Naciones Unidas para el Desarrollo Social, 2007.

Vilches, Carlos. "La acogida a la población inmigrada que reside en Navarra". Pamplona: Taller de Sociología s. I., 2007.

San José, Begoña. "No solo queremos cuidar ni queremos hacerlo solas", Apuntes Ciudadanos 4 (2011): 157-174. 